\title{
Application and perspectives for interoperable systems in Italy and Europe
}

\author{
R. Bozzo ${ }^{1}$, R. Genova ${ }^{2} \&$ F. Ballini ${ }^{2}$ \\ ${ }^{I}$ Department of Electrical Engineering, University of Genoa, Italy \\ ${ }^{2}$ Inter-University Centre of Transport Research, Genoa, Italy
}

\begin{abstract}
A rapid transit system represents one of the main growth areas of the railway business developed to solve the enhanced mobility request. New solutions have been applied in order to simplify and to improve public transport services, without changing trains and providing a fast, direct link from the city to the outskirts. The solutions are interoperable transport systems (like "light rail" very similar to the "Stadtbahn" approach, "tram-train" and "train-tram").

The "tram-train" concept indicates vehicles which operate on railway lines in suburban areas, but that are also able to work on a tramway net to supply a capillary service in the urban area.

In central Europe a few cities have planned different tram-train solutions: Karlsruhe, Saarbrücken, Chemnitz and Kassel realised the "heavy" model (train performances and technical standards similar to railway rolling stock). Other cities choose "light" systems, adopting vehicles more similar to the tramway design (Nordhausen, Zürich, Vienna, etc.).

The tram-train represents the missing link between urban tramway and railway systems, whose transport capability depends only on how the infrastructures are used (railway or tramway nets).

Another non conventional and lower cost model is the "Stadtbahn" which have diverted in-town sections of their system underground; in some of these cases, tunnels have been built to accommodate full metro trains if desired (Stuttgart, Frankfurt a/M, Bochum, Köln, etc.).

In Italy "metrotranvia" lines are to be found in Milan and Turin, based on the light rail model: in Turin the rolling stock have been built with peculiar characteristics (floor height $550 \mathrm{~mm}$ for boarding at platform level). Other interesting Italian interoperable systems are the "Tram delle Valli" in Bergamo
\end{abstract}


and the Sassari tramway (950 mm track gauge, the same as the interconnected railway local net "Ferrovie della Sardegna") and, in the near future, the renewed interurban tramway line Milano-Desio, (extended to Seregno) with estimated costs amounting to 214 million Euros. Finally, the Torino-Torre Pellice, will be the first tram-train application in Italy

Keywords: local public transport, interoperable systems, economic impacts.

\section{Means of transfer chosen by the users}

Since the end of the Second World War mobility demand has undergone deep seated changes, both from the quantitative and qualitative point of view, mainly following the changed conditions of work and settlement.

Today journey times have taken on, together with comfort and safety, an ever greater importance, just as the demand for transfers not only from the outskirts to the centre but from metropolitan areas to the central zones of cities is continuously increasing.

This phenomenon requires suitable responses from public transport, which in recent years has shown an interesting recovery but not sufficient, however, to supply a valid alternative to private mobility, now so well rooted in the habits of citizens especially in erratic journeys or those which require "breaks of load".

For transport supply one does not require only a suitable sizing, but also economic and environmental sustainability, with a careful look at the visual impact and street furniture.

Therefore, the problem appears to be extremely complex both for transport companies and for the public administration. Technological innovation plays an essential and at the same time delicate role, making a higher number of solutions available compared to the past, but facing decision makers with delicate problems in the choices to be taken.

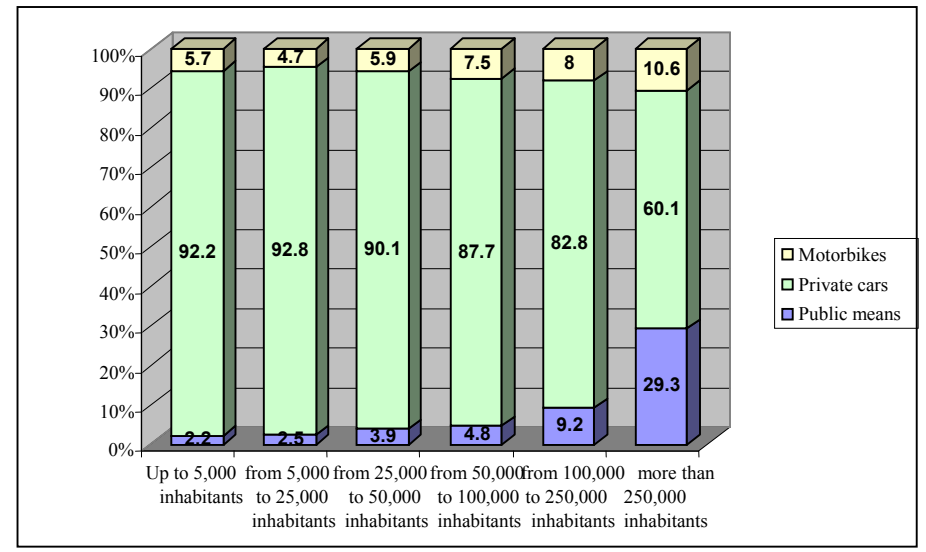

Figure 1: Means of transfer chosen on the basis of the size of the urban centre. 
Today, the trends in progress are various, first of all the revival of the tramway system lived as an instrument for the best exploitation of town planning for cities, which are being redesigned through it. In more detail, Italy appears with a high propensity to the use of private means (two or four-wheeled) indeed the rate of motorisation is among the highest in the European Union, with 590 cars per thousand inhabitants in 2005, passed only by Luxembourg.

Figure 2 shows the results of a survey conducted by ISFORT between 2004 and 2006 with regard to the satisfaction expressed by the citizens of mediumlarge towns with regard to the public transport service delivered, respectively, by bus and tram (graph on left) and by underground (graph on right). As it is possible to see, the judgement expressed in 2006 for bus and tram appears negative (little or not at all satisfied) for about $35 \%$ of those interviewed, with a slight improvement compared to the previous year but a marked worsening compared to the year 2004, where dissatisfaction with the service was manifested by about $29 \%$ of the sample. The underground service was judged considerably better with a quota of dissatisfied on average of around $20 \%$ with a minimum of $16 \%$ in 2006. Since an action aimed at reviving public transport requires in depth study, with separation of opinions between road and rail systems such as trams, there emerges a marked satisfaction for mass rapid transport systems [1].
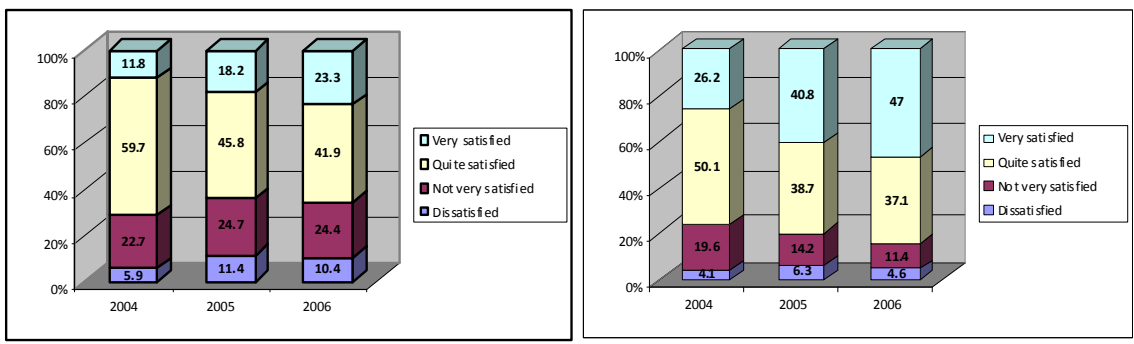

Figure 2: $\quad$ Satisfaction expressed by users in medium-large towns for the public transport service [2].

For medium-small centres, where mass rapid transport systems are not in themselves applicable, technology however makes interoperable systems available, which allow one to limit investments in infrastructures using the existing networks and drastically reducing the breaks of load.

\section{The reasons at the base of the disaffection for public transport in Italy}

The reasons at the base of the disaffection for public transport are of both a social and technical nature. Indeed, along with the simple habit of total autonomy in the journey, the points of major criticality are, in order of importance in the users' perception: 
1. journey times, considered non competitive compared to those of the private means and often very difficult to quantify with certainty in advance;

2. accessibility of the public means (understood as ease of use) is lower than the private means, and the need for breaks of load;

3. capillarity of the service;

4. insufficient level of comfort, mainly attributable to overcrowding but also to parameters now assessed as fundamental, such as the level of cleaning, the efficiency of the air conditioning plant, the level of safety and the difficulty of entering the carriage due to the survival of vehicles with the floor not lowered;

5. correspondence of the service with the real needs, with particular reference to the frequency of the runs, the design of the routes and the networks.

The last point, in particular, is confirmed by the data contained in the National Transport Account 2007 and summarised in figure 3, from which a heavy imbalance emerges between supply of and demand for transport. This imbalance is more evident in the urban service ( 71.7 billion places per $\mathrm{km}$ supplied against 11.6 billion passengers per $\mathrm{km}$ transported) compared to the extraurban one ( 70.4 billion places per km supplied against 18.1 billion passengers per $\mathrm{km}$ transported). Even though, $25.7 \%$ of coverage of the places supplied for the extraurban service does not seem to be an appreciable result either for the covering of the costs, or for the satisfaction with the service. Within towns, this coverage is even lower: just $16.2 \%$.

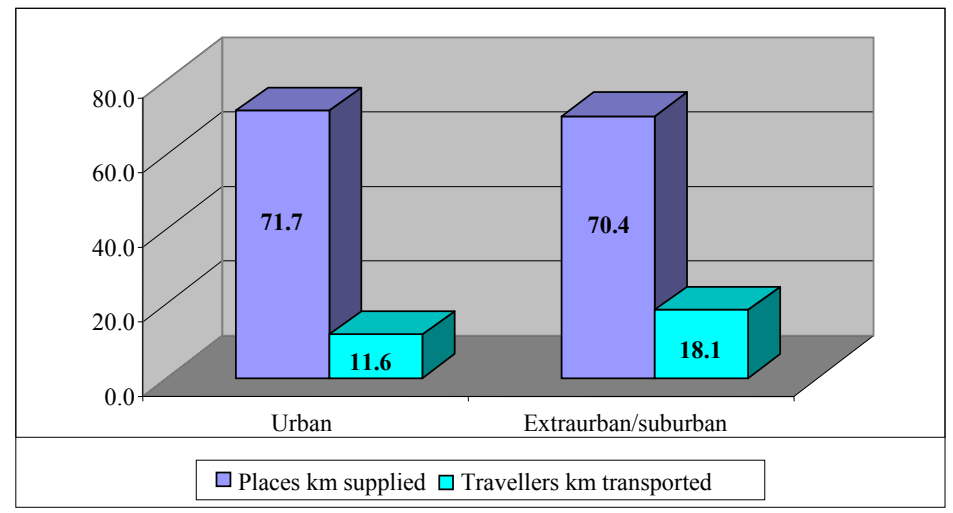

Figure 3: Comparison between passenger $\mathrm{km}$ transported and places $\mathrm{km}$ supplied (billions) [3].

To all this one must add the slow evolution of the concept of sustainable mobility toward s an idea of "enlarged comfort" of towns, where the reduction of private mobility and recourse to public transport systems with low emissions 
becomes functional to urban upgrading. This derives from a greater environmental awareness among the population, but also from the awareness that such a renewed context represents the driving force for the growth of the wealth of the territory. However, a public transport system cannot limit itself to satisfaction of environmental parameters and user satisfaction, it must also be efficient to bring together the liveability of towns with the economic sustainability of services.

These objectives may be reached through the use of innovative, high-capacity systems that make that level of service available that allow one to acquire market shares (new users) and therefore to improve the urban centre, both from the point of view of congestion by traffic and from the point of view of atmospheric and acoustic pollution.

\section{Comparison of the costs and technologies for the public transport}

Table 1 permits a comparison of the innovative and traditional technologies available for the running of Public Transport of people in urban areas and shows a comparison between the transport capacities of different systems obtained hypothesising a frequency of service equal to about three minutes. It is clear how depending on the level of mobility demand expressed by the urban zone the service is sized and the choice of the most suitable means of collective transport is made.

An exact consideration of the levels of present use and a correct estimate of those that may possibly be attracted with innovative modes and/or means of transport is indeed presupposed fundamental for both the economic and technical sustainability of the service.

As highlighted in table 1, the consumption, expressed for uniformity of comparison in grams of oil equivalent, are very different from one another depending on the transport technology examined.

The typology of hybrid bus considered is that of the most innovative which allow an energy saving of about $20 \%$ compared to traditional thermal vehicles. Also for what concerns trolley buses the consumption was estimated for those of the latest generation equipped with energy recovery systems (e.g. supercapacitors) and for which one estimates a saving of electrical energy of the order of $25 \%$.

With particular reference to trolley buses with supercapacitors, the first series of vehicles, of 18 metres, were delivered at the start of 2009 to the ATM in Milan.

Analysing consumption per $\mathrm{km}$ travelled one sees how the "classical" underground is that which expresses the highest values: 538 grams of oil equivalent per $\mathrm{km}$, while the trolley bus is the one with the lowest energy consumption with a maximum value for the vehicle of 24 metres equal to 359 goe $/ \mathrm{km}$.

Finally, considering the specific consumption (which also takes into account the capacity of the means) one sees how the data favour high-capacity systems: 
Table 1: Comparison between urban transport systems - passengers transported consumption and costs.

\begin{tabular}{|c|c|c|c|c|c|}
\hline $\begin{array}{l}\text { Type of } \\
\text { vehicle }\end{array}$ & $\begin{array}{c}\text { Passengers } \\
\text { transported /h } \\
\text { per direction }\end{array}$ & $\begin{array}{c}\text { Estimated } \\
\text { consumption } / \mathbf{k m} \\
\left(\mathrm{goe} / \mathbf{k m}^{*}\right)\end{array}$ & $\begin{array}{c}\text { Estimated } \\
\text { specific } \\
\text { consumption } \\
(\text { goe/pkm**) }\end{array}$ & $\begin{array}{c}\text { Cost of } \\
\text { vehicle } \\
\text { €k }\end{array}$ & $\begin{array}{c}\text { Cost of } \\
\text { infrastructure } \\
€ \mathbf{k} / \mathbf{k m}\end{array}$ \\
\hline $12 \mathrm{~m}$ bus & 1500 & 368 & 24.2 & 310 & $0-100$ \\
\hline $18 \mathrm{~m}$ bus & 2500 & 423 & 20.4 & 380 & $0-100$ \\
\hline $24 \mathrm{~m}$ bus & $3,500-4,000$ & 478 & 17.3 & 500 & $0-100$ \\
\hline $\begin{array}{l}12 \text { m hybrid } \\
\text { bus }\end{array}$ & 1500 & 294 & 19.3 & 460 & $0-100$ \\
\hline $\begin{array}{l}18 \text { m hybrid } \\
\text { bus }\end{array}$ & 2500 & 338 & 16.3 & 570 & $0-100$ \\
\hline $\begin{array}{l}24 \text { m hybrid } \\
\text { bus }\end{array}$ & $3,500-4,000$ & 382 & 13.8 & 900 & $0-100$ \\
\hline $\begin{array}{l}12 \mathrm{~m} \text { trolley } \\
\text { bus }\end{array}$ & 1500 & 276 & 18.2 & 500 & $400-600$ \\
\hline $\begin{array}{l}18 \mathrm{~m} \text { trolley } \\
\text { bus }\end{array}$ & 2500 & 317 & 15.3 & 800 & $400-600$ \\
\hline $\begin{array}{l}24 \text { m trolley } \\
\text { bus }\end{array}$ & $3,500-4,000$ & 359 & 13 & 1000 & $400-600$ \\
\hline Tram & $4,000-6,000$ & 488 & 15 & $\begin{array}{c}2,000- \\
3,000\end{array}$ & $7,000-10,000$ \\
\hline Underground & $\begin{array}{c}15,000- \\
30,000\end{array}$ & 538 & 10 & 9000 & $12,000-50,000$ \\
\hline
\end{tabular}

* goe $/ \mathrm{km}$ : grams of oil equivalent per $\mathrm{km}$

** goe/pkm: grams of oil equivalent per passenger $\mathrm{km}$

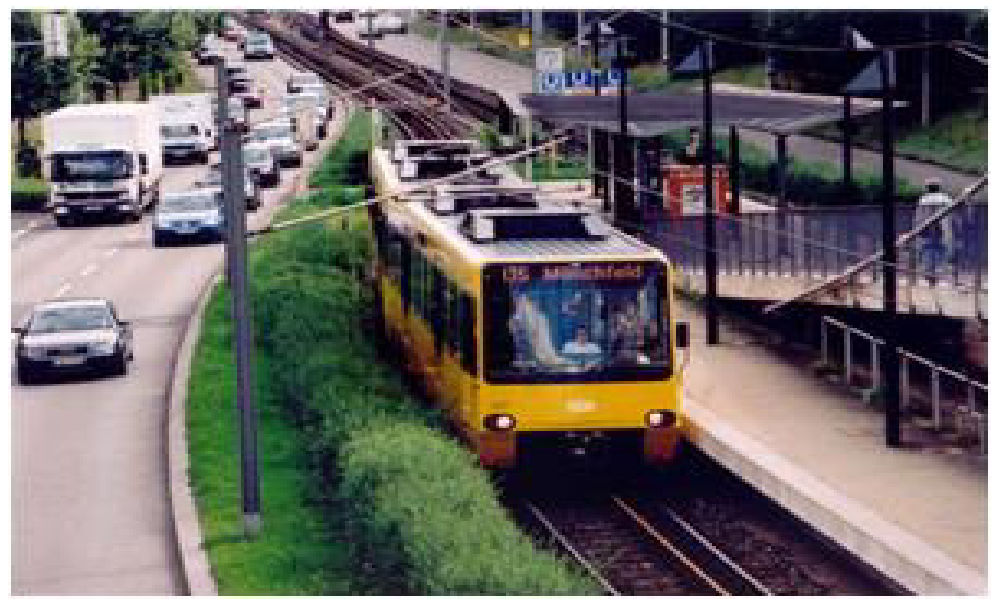

Figure 4: $\quad$ Stuttgart "Stadtbahn" system [4]. 
the lowest specific consumption expressed in grams of oil equivalent per passenger $\mathrm{km}(10$ goe $/ \mathrm{pkm})$ is that of the underground, while the highest value is that of the thermal bus of 12 metres ( $24.2 \mathrm{goe} / \mathrm{pkm})$.

It is clear that for the underground plant that transport up to 30 thousand passenger hours in each direction with a capacity up to 1200 passengers per train (standard composition with 6 vehicles) the energy consumption attributable to each passenger $\mathrm{km}$ transported is drastically cut winning the challenge of the most "environmentally friendly" means among those considered, followed by the other plant with a fixed path, trams, which have a specific consumption of 15 goe/pkm and by trolley buses of 24 metres $(16.9$ goe $/ \mathrm{pkm})$ which are vehicles that have only recently come onto the market.

The innovations of the tramway sector have been fundamental for the progressive integration with the existing railway systems and with the classical underground and the creation of interoperable systems, in particular of the tramtrain system [5] which represents one of the most interesting progresses in the transport field in recent years and the new trend for the sector.

With the term "tram-train" one defines a family of rolling stock that carry out services on railway stretches in a peripheral or territorial environment, but which are able, thanks to suitable links, to use normal tramway lines, supplying a capillary service of connection within town centres as well as between town centres far from one another.

The system [6] is competitive and efficient, particularly thanks to the following characteristics:

- minimisation of investment costs thanks to the use of already existing railway infrastructures, possibly reusing disused railway lines;

- possibility of increasing the number of stations along the railway line keeping the same journey times for a train;

- reduction of running costs compared to an equivalent railway system, the tramway system needing only one operator on board;

- increase of the commercial speeds in suburban stretches and drastic reduction of the breaks of load.

Different solutions have been adopted by the realities which have adopted tram-train systems. In Karlsruhe, Saarbrücken, Chemnitz and Kassel the so called "heavy" models have been preferred i.e. with trains that are similar in characteristics and dimensions to railway electric locomotives (or railcars), while in other cases "light" models have been adopted i.e. with a more reduced profile and more similar to a tramway vehicle.

Karlsruhe, already in 1992, presented itself as a pilot project for the running of tram-trains [5]: today there are 11 lines active of the "S" type with a total extension of the network of $468 \mathrm{~km}$. The 36 trains first supplied of GT8100C/2SY type were joined in the years 1997-1999 by another 79 GT8100D/SY-M, some of which equipped with toilet facilities.

In the town of Saarbrücken 28 "Flexity Link" trains have been operating on the $25.5 \mathrm{~km}$ of network with 23 stops/stations since 1997. 
Table 2: $\quad$ Comparison between different transport systems.

\begin{tabular}{|l|c|c|c|c|}
\hline \multicolumn{1}{|c|}{$\begin{array}{l}\text { System } \\
\text { (vehicl) }\end{array}$} & $\begin{array}{c}\text { Transport } \\
\text { capability } \\
\text { [pass/h } \\
\text { direction] }\end{array}$ & $\begin{array}{c}\text { Infrastructural } \\
\text { costs } \\
{[\mathbf{k €} / \mathbf{k m}]}\end{array}$ & $\begin{array}{c}\text { Vehicle } \\
\text { length } \\
{[\mathbf{m}]}\end{array}$ & $\begin{array}{c}\text { Vehicle } \\
\text { power } \\
{[\mathbf{k W}]}\end{array}$ \\
\hline Tram & $4,000-6,000$ & $5,000-10,000$ & $30-50$ & $250-500$ \\
\hline $\begin{array}{l}\text { Light rail } \\
(*)\end{array}$ & $8,000-12,000$ & $20 ., 000$ & $20-30$ & $400-800$ \\
\hline $\begin{array}{l}\text { Under- } \\
\text { ground(**) }\end{array}$ & $8,000-30,000$ & $12,000-50,000$ & $12-25$ & $300-600$ \\
\hline $\begin{array}{l}\text { Tram-train } \\
(*)\end{array}$ & $3,000-5,000$ & typically existing & $30-40$ & $400-600$ \\
\hline
\end{tabular}

Length and power referred to single unit, (*) multiple coupling up to 3 units, $(* *)$ multiple coupling up to 8 units.

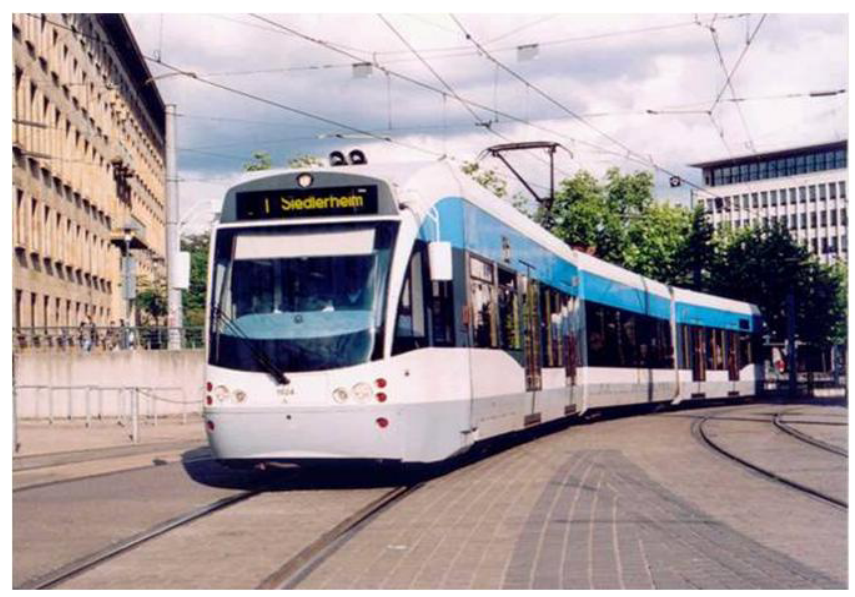

Figure 5: "Heavy" model train system.

In Chemnitz, from which originates the transport model going by the same name, since 200210 Variobahn tram-trains have been operating which serve the $23 \mathrm{~km}$ of regional network between Altchemnitz and Stollberg. In the early nineties (after the fall of the Berlin wall and with the return of the name of the town of Karl-Marx-Stadt to Chemnitz)a feasibility study was carried out that envisaged the creation of a mobility system on a territorial scale by means of the reconversion of non-electrified railway lines for the running of tram-trains.

The RegioTram project of Kassel saw the opening in 2007 of 4 lines (RT1RT2-RT3-RT4) with an extension of $122 \mathrm{~km}$ on which 18 Alstom RegioCitadis 
version E/E (750 cc - 15kV 16 2/3 Hz) and 10 Alstom RegioCitadis version E/D (750 cc-diesel) operate destined to the non-electrified lines.

In France the "T4" line was opened in November between Aulnay-sous-Bois and Bondy in the suburbs of Paris. The plant is operated by the same SNCF on the site of a previous railway, while the other three Parisian lines are run by RATP. Alstom will deliver to SNCF a good 200 tram-trains, which will benefit besides the area of Lyons, the countryside of the Loire, the Rhône-Alpes region, the Ile-de-France and the town of Strasbourg.

In Italy the use of tram-trains is envisaged on the railway stretch from Turin to Torre Pellice: the Piedmont Region has foreseen a contribution of $€ 20 \mathrm{M}$ for the purchasing of three vehicles and for adjustment of the infrastructure. In the urban environment its running on the tramway network of the Piedmont regional capital is foreseen.

The tram-train can also be associated with all the interoperable tramways, among which are to be recalled Line 10 in Basel, which connects Basel with the small town of Rodersdorf running along a stretch also in French territory on which there is the stop of Leymen: the non urban stretch runs on the route of an old reconverted railway line. Still in Basel line 8 which will be extended as far as Weil am Rhein in Germany, confers the town network a unique feature of internationality.

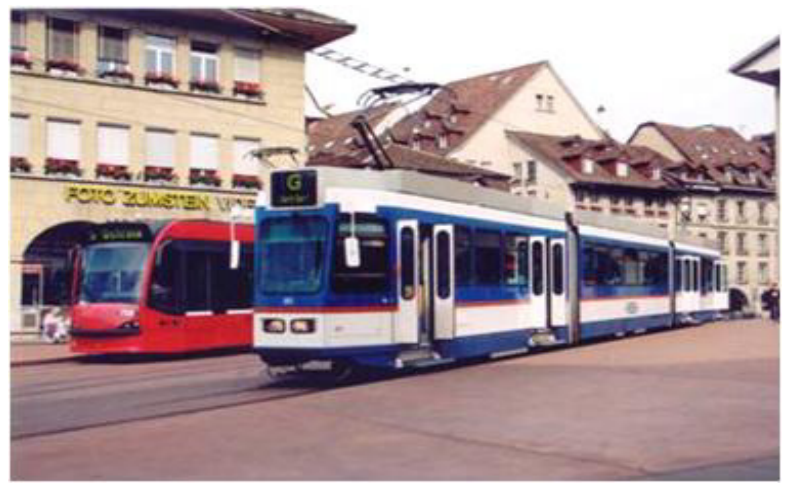

Figure 6: The railway line Bern-Worb Dorf.

In Berne Line $\mathrm{G}$ can be cited which arrives as far as Worb Dorf; in Vienna the Wiener Localbahnen runs the urban service on a tramway network and the same goes for the Forchbahn in Zurich, which is inserted, at the level of service model of rhythmic timetable in the S-Bahn town system.

From the point of view of applications, in 2004 the five transport companies operating in the basin of the Rhine and Neckar gave life to a unique consortium, the RNV (Rhein-Neckar-Verkehr GmbH) which, thanks to the infrastructures present and their total interconnection, offers a territorial service complementary to the railway network run by DB. 


\section{Conclusions}

In conclusion we can say that the use of interoperable systems for local public transport (extra urban and suburban) is far more developed in other European countries than Italy where this development is hampered by rigid regulation on the use of rail networks.

As we mention in this article, interoperable systems have a positive impact on efficiency, effectiveness and passenger comfort and are often critical to the success of local public transport areas within which they operate. Consequently, their presence significantly affects the number of people who turn to public transport services rather than the convenience of private transport. It is also critical in curbing congestion, air and noise pollution.

\section{References}

[1] S. Migliaccio, Trasporti pubblici di qualità, MobilityLab, n. 22, Bimestre Luglio - Agosto, 2008.

[2] ISFORT - "Audimob" observatory of mobility of Italians. - Data 2005

[3] National Transport Account ed. 2007 - Data 2005.

[4] R. Bozzo, R. Genova, I sistemi "STADT-BAHN”: un modello di ferrovia cittadina, MobilityLab n. 17, Settembre - Ottobre 2007.

[5] M. Novales, M. R. Bugarin, A. Orro, Un nuovo concetto nel trasporto urbano : il tram-treno, Ingegneria Ferrovia, n. 10, p. 741, 2001,

[6] F. Perticaroli, Sistemi elettrici per i trasporti, Seconda edizione - Casa Editrice Ambrosiana, Milano, Gennaio 2001. 